\title{
Primary care of patients with mental disorder in the community ${ }^{\star}$
}

\author{
Michael Shepherd
}

When Richard Titmuss gave a paper in 1961 on "Community care - fact or fiction?" although the term "community care" had appeared on government documents for more than a decade, its meaning had not been seriously questioned. Titmuss commented:

It has been one of the more interesting characteristics of the English in recent years to employ idealistic terms to describe certain branches of public policy. The motives are no doubt well-intentioned, the terms so used express, in civilised phrases, the collective aspirations of those who aim to better the human condition. It is necessary to remember, however, that this practice can have unfortunate consequences. Public opinion - in which I include political opinion - may be misled or confused. If English social history is any guide, confusion has often been the mother of complacency. In the public mind, the aspirations of reformers are transmuted, by the touch of a phrase, into hard-worn reality. What some hope will one day exist is suddenly thought by many to exist already.

As the ambiguities to which Titmuss alluded arise principally from the various concepts of "community" it is useful to look briefly at the origins and definition of this notion.

\section{Origins of the term community}

In its historical perspective the notion of community is a dominantly non-medical concept, and one that is central to the European sociological tradition. Robert Nisbet goes so far as to include it as one of the five fundamental elements of nineteenth century sociology, alongside the concepts of authority, status, alienation, and the sacred. ${ }^{2}$ In England much of the thinking had been foreshadowed by the prophetic visionary, William Godwin. "Virtue and happiness," wrote Godwin, "can only spring from socially considered and constituted aims ... the true solitaire cannot be considered as a moral being. ... His conduct is vicious, because it has a tendency to make him miserable." This theme was to be developed tellingly by Godwin's daughter, Mary Shelley, in the words of her famous fictional monster, who cries out to its creator Victor Frankenstein: "My vices are the children of a forced solitude that I abhor, and my virtues will necessarily arise when I live in communion with an equal."

In one sense Karl Marx's theory of communism is no more than an elaborate socioeconomic footnote to this outlook and the development of the idealised revolutionary commune gave further impetus to the notion. The most searching contribution to communal thinking, however, was provided by Ferdinand Tönnies. In Community and Society, published in $1887,{ }^{5}$ he constructed a typologically dichotomous framework and drew a seminal distinction between community as "Gemeinschaft" and community as "Gesellschaft." These two German words have proved irreplaceable. Gemeinschaft refers to a group in which the relations between people are direct, profound, and all embracing. It is a form of collective or a social unit that usually comprises $(a)$ a group sharing a defined space or geographical area and $(b)$ a group sharing common traits. Prime examples are the family or the tribe. By contrast, Gesellschaft is an association of individuals whose relationships are largely indirect, relatively superficial, and relate only to parts of the lives or

personalities of those concerned. It is based on a kind of formalised relationship or sentiment. For Tönnies modern society was characterised by a movement from Gemeinschaft to Gesellschaft, which he saw as a drift towards a state of uprootedness which he deplored.

It is an attractive Germanic hypothesis but hardly susceptible to direct examination. None the less, it stimulated a large volume of work on the precise meaning of the word "community." Hillery traced 94 definitions of the term, ${ }^{6}$ and the task of pinning it down has been called " $a$ thriving intellectual pastime of sociologists." Even so, this tower of Babel did not prevent the emergence after the first world war of a series of important empirical inquiries. Prominent among them were the urban studies of the Chicago school in the 1920s and 1930s, including the pioneering studies of Faris and Dunham on the distribution of psychotic illness in Chicago. ${ }^{8}$ These workers subdivided the community into demarcated areas to assess the relative merits of the "breeder" and "drift" hypothesis, a prime example of Gesellschaft thinking based on the association of attack rates with demographic and socioeconomic factors.

After the second world war the mental hospital became the focus of attention for community minded workers. The study of institutions as small communities was pioneered by social theorists like Erving Goffman ${ }^{9}$ and William Caudill. ${ }^{10}$ Here is Goffman's description of the asylum as an example of a total institution:

First, all aspects of life are conducted in the same place and under the same single authority. Second, each phase of the member's daily activity is carried on in the immediate company of a large batch of others, all of whom are treated alike and required to do the same thing together. Third, all phases of the day's activities are tightly scheduled, with one activity leading to a prearranged time into the next, the whole sequence of activities being imposed from above by a system of explicit formal rulings and a body of officials. Finally, the various enforced activities are brought together into a single rational plan purportedly designed to fulfil the official aims of the institution.

This might pass as a desirable form of Gemeinschaft, and the widely bruited virtues of the so called "therapeutic community" were given a medical dimension by physicians with an interest in group dynamics. They did not, on the whole, question the role of the institution as the appropriate milieu for mentally sick people, and their interest in psychodynamic theory and practice overlapped with that of the non-medical workers.

\section{Community psychiatry}

The medical concern with communal factors was quickened when the role of institutional care came to be seriously questioned. The origins of this debate go back at least to the Gheel colony (a therapeutic community in Belgium), but the term "community psychiatry" did not come into its own until the 1950s. Though its precise meaning has been disputed, most workers in the subject would probably subscribe to the view that it be "... identified as the best possible clinical care delivered to individuals and to population groups in community settings. Services are delivered

World Psychiatric

Association and the Spanis

Neuropsychiatric

March 1989. 




King Lear. (Reproduced with permission from "The Medical Mind of Shakespeare" by A C Kail. Williams and Wilkins, 1986.)

in communities and their institutions rather than within the setting of total institutions (state hospitals, asylums, etc)." psychiatric disorders, particularly the functional psychoses, and on mental defect. In line with this opinion the principal concerns of community psychiatrists have been with the extramural fate and the management of patients suffering from these conditions who were formerly regarded in largely institutional terms.

The impetus of this movement towards community care derived from various sources. On the biomedical front the new wave of psychotropic drugs made the treatment of symptoms a means of discharging patients from hospital so that an open door policy could be considered realistically. In fact, however, the evidence suggested that this trend preceded large scale pharmacotherapy in some illnesses, ${ }^{12}$ and the principal sources of the movement were not primarily medical in origin. The policymakers argued in its favour largely on the grounds that it would be cheaper than the high cost of hospital beds, and they were supported by a motley group of civil libertarians, who maintained in the name of various creeds and ideologies that mental hospitals were effectively prisons, depriving their inmates of "freedom" under an authoritarian medical regime from whose yoke discharge represented a release and a return to normal life. The role of the physician was correspondingly demeaned, and the doors were opened to a wave of non-medical mental health workers - social workers, nurses, counsellors, self help groups, and the patients - who laid claim to equal rights and authority.

But what was to be the fate of these patients? Titmuss anticipated the current situation nearly 30 years ago.

To scatter the mentally ill in the community before we have made adequate provision for them is not a solution; in the long run not even for HM Treasury. Considered only in financial terms, any savings from fewer hospital in-patients might well be offset several times by more expenditure on the police forces, on prisons and probation officers, more unemployment benefit masquerading as sickness benefit, more expendi- ture on drugs, more research to find out why crime is increasing. At present we are drifting into a situation in which, by shifting the emphasis from the institution to the community - a trend which, in principle and with qualifications, we all applaud-we are transferring the care of the mentally ill from trained staff to untrained or ill-equipped staff or no staff at all.

Time has underlined the truth of his verdict. The communal resources designed to cope with discharged patients tended to take the form of a series of halfway institutions where management depended largely on regulated group discussion with patients who, it was assumed, were potentially non-violent, suffering from self limiting disorders that needed no more than discontinuous care, and would be particularly responsive to a regimen that would at least modify their attitudes and behaviour. It was not foreseen that many patients would indulge in antisocial conduct or need 24 hour supervision or be incapable of caring for themselves. Little was provided such people, and the illusion that discharged patients would re-enter and become integrated with a wider Gesellschaft was soon exposed. It is the oldest form of Gemeinschaft, the family, which has had to shoulder the burden, often at appalling human and financial cost.

\section{A government document}

In 1984 in the United Kingdom the impact of deinstitutionalisation had reached such dimensions that for the first time in any country a specially constructed committee of a nationally elected representative body, the House of Commons, initiated a large scale inquiry on the community care of the mentally ill and mentally handicapped in the UK. ${ }^{13}$ As the report makes clear, the subject is "not a subject for partisan politics. It is however a highly political subject, where the potential for improving the lives of hundreds of thousands of our fellow citizens is as great as the penalty for misjudgements."

The report is remarkably comprehensive, reflecting the conclusions of 11 experienced politicians of differing backgrounds and shades of opinion who spent many months collecting evidence and visiting centres inside and outside the United Kingdom. A few of its conclusions merit emphasis.

(1) The phrase "community care" means little in itself. It has in fact come to have such general reference as to be virtually meaningless. It has become a slogan, with all the weakness that that implies ( $\mathrm{p} \mathrm{x}$ ).

(2) Earlier community care policies were embarked on in the apparent belief that it was the institutions which created many of the disabilities of those within them, and that modern medical or psychological techniques would lead to a massive reduction in the need for long-term care. There are now only vestiges of such a blithely over-optimistic attitude. While the disabilities of long-stay patients may well be heightened by institutional care, the simple facts are that there is little prospect of major change for the better for many mentally disabled people... informed opinion is slowly returning to the idea that there will always be a substantial number of mentally disabled people who are entitled to some sort of protection and support, which may involve their partial withdrawal from the rest of the community ( $p$ xvi).

(3) The pace of removal of hospital facilities for mental illness has far outrun the provision of services in the community to replace them ( $\mathrm{p}$ xviii).

(4) The almost obsessive concentration in public policy on the mechanisms for "getting people out of hospital" has sometimes obscured the basic fact that most mentally ill or handicapped people already live in the community, whether with their families, in lodgings, group homes, hostels or private accommodation ( $\mathrm{p} \mathrm{xv})$.

\section{Community and neighbourhood}

This last observation acknowledges that even when the fate of those individuals with mental disabilities is 
considered severe enough to necessitate contact with institutions the medically structured Gemeinschaft has to be replaced by a broader dominantly social notion of Gesellschaft. In modern society, especially in urban areas, some sociologists have focused their attention on the concept of neighbourhood as an effective resource for community care. Viewing community care in general as "the provision of help, support and protection to others by lay members of societies acting in everyday domestic and occupational settings," have defined neighbourhood care in particular as "a mobilisation of local energies and resources to achieve levels of indigenous concern and support which complement, supplement and progressively contain the need for external stability and voluntary services in specified respects."

Several empirical studies have been carried out to investigate the complex relation between these informal modes of neighbourhood care and the formal methods of "community treatment"-that is, extensions of hospital care adopted by policymakers. The theoretical underpinning of this work, which has stimulated much discussion on the vexed relation between altruism and reciprocity, touches on some fundamental aspects of human behaviour. Practically, however, what stands out is the conclusion that, "Professional roles and the roles of informal care-givers are different, there exist considerable problems in attempting to integrate them." 15 These differences arise because local neighbourhood care derives from what Max Weber called "traditional action," while health and social services personnel adopt an orientation to rational action based on professional training and standards.

\section{Community care and primary care}

The relevance of these factors for providing community care for patients with mental disorders is apparent. Once the psychiatric patient has left the protected institutional environment he or she enters a universe in which care is provided partly by community treatment, but principally by formal and informal caregivers among whom the medically qualified professional plays only one part. Inasmuch as these people suffer from disabilities with a medical component, however, they require medical care in some measure. Who should provide it?

The answer of the House of Commons Social Services Committee was unequivocal: "Community care depends to a large extent on the continuing capacity of GPs to provide primary medical care to mentally disabled people." This statement reflects the growing awareness of the role of the general practitioner in managing mental disorder, echoing the conclusion of a World Health Organisation report that "the primary care team is the cornerstone of community psychiatry." 16 Underlying this view is the recent realisation that the bulk of mental illness in any community never comes to the attention of the psychiatric specialist. Self styled community psychiatrists, who might have been expected to acknowledge this, tend to dismiss it. As one of them asserted:

A population of 60000 would yield 1000 psychiatric patients in the care of 3 psychiatrists. There will also be about 24 GPs in the area. These doctors, however, cannot give psychiatrists much help, for in our health service family doctors are already seeing the bulk of the patients with socioeconomic problems."

As Goldberg and Huxley pointed out, the reason for such thinking is "that psychiatrists base their concepts of mental illness on the highly selected sample of patients who are referred to them.... this selection process is therefore important in determining what is or will be thought of a psychiatric case."
In all countries with a two tiered system of medical care the referring agents are the primary care physicians. Much of the factual evidence bearing on their central role was originally furnished by our survey of psychiatric illness in general practice more than 20 years ago. " "In a year the average general practitioner will deal with 200 minor emotional illnesses; . . . twelve patients will present with severe depression; . . . he will refer 11 patients for psychiatric advice and 4 to child guidance clinics; and ten of his patients will be admitted to psychiatric wards or hospitals. Fifty-five of his patients with recurrent or chronic mental illness will be living in the community."20

Such data bring a radically different perspective to the concept of community psychiatry. They have since been confirmed by workers throughout the world. They justify the need to employ a sociomedical framework to do them justice, and they bring psychiatry into the broad framework of public health. In consequence, teamwork is indispensable, and the general practitioner's activities extend to collaborating with non-medical colleagues (social workers, nurses, psychologists) in one direction and with medical colleagues (psychiatrists) in the other. Different systems of medical care affect the precise nature of the primary care physician, but he or she remains the physician of first contact, a part of the community, and best placed to act as the family doctor and view the patient in the setting of Gemeinschaft.

\section{Models of collaboration between specialists in general medicine and psychiatry}

Some years ago we sent a questionnaire to all consultant psychiatrists in England and Wales asking whether their junior staff were working in general practice. ${ }^{21}$ A fifth gave a positive response. In the past decade this service has increased, chiefly as a result of the activities of younger consultant psychiatrists and more as a spontaneous movement by general practitioners and psychiatrists, rather than as the result of any official policy.

Three principal models of collaboration were suggested. ${ }^{22}$ The first, the "replacement model," envisaged the replacement of general practitioners and psychiatrists or other specialists to provide the "first contact" for patients with psychiatric disorders. This model underlines the development of community mental health centres in the United States, but it has had little support in Britain because of the structure of the medical care system.

The second, the so called "increased referral" model, encouraged general practitioners to refer more patients to facilities that already exist in hospital. This in turn implies the need for more psychiatrists. The third, the "liaison attachment model," depends on the acceptance of the proposition that some at least of the work of psychiatric specialists is best conducted out of hospital in the setting of general practice itself. It is clearly necessary to evaluate these models, and their relative advantages and disadvantages are being studied.

\section{Conclusion}

Our findings 25 years ago led us to conclude that, "Administrative and medical logic alike... suggest that the cardinal requirement for improvement of the mental health services in this country is not a large expansion and proliferation of psychiatric agencies, but rather a strengthening of the family doctor in his therapeutic role." Time has endorsed that view, but it is not always remembered that we went on to say: "It would, however, be naive to contemplate such a development without an awareness of its implications 
for other aspects of the practitioner's function not directly connected with mental illness. The family doctor's role in the treatment of psychiatric disorders can be defined clearly only in the perspective of his larger relationship to the medical services and society." It follows that if the term community psychiatry is to have any meaning it must be viewed in the light of the role and function of the primary care provider in the broader framework of the structure and value system of each society. Such an issue entails many contingent factors, such as political objectives, staffing, money, professional status, and public expectations. Each system of medical care introduces variations on this basic theme, and a recently published WHO report suggests that the movement in this direction is underway on a wide front. ${ }^{23}$ Experiment, evaluation, and comparison are needed if we are to turn Titmuss's fictions of yesterday into the facts of tomorrow.

1 Titmuss R. Community care-fact or fiction? In: Freeman H, Farndale J, eds. Trends in the mental health services. Oxford: Pergamon, 1963:221-5.

2 Nisbet R. The sociological tradition. London: Heinemann, 1966.

3 Godwin W. In: Priestley FEL, ed. Enquiry concerning political justice. Toronto: Ryerson Press, 1946:311.

4 Shelley M. Frankenstein. London: Penguin, 1987.

5 Tönnies F. In: Loomis C, trans, ed. Community and society. New York: Harper Torchbook, 1963.

6 Hillery GA. Definitions of community: areas of agreement. Rural Sociology 1955;50:20-35.
7 Azarya VG. Community. In: Kuper A, Kuper J, eds. Social science encyclopaedia. London: Routledge and Kegan Paul, 1985:135-7.

8 Faris RJ, Dunham HW. Mental disorders in urban areas. Chicago: University of Chicago Press, 1939.

9 Goffman E. Asylums. Harmondsworth: Penguin, 1968

10 Caudill W. The psychiatric hospital as a small society. Cambridge, Mass: Harvard University Press, 1958.

11 Astrachan B. Introduction. In: Serban G, ed. New trends of psychiatry in the community. Cambridge, Mass: Ballinger, 1977.

12 Shepherd $M$. Therapeutic problems with psychotropic drugs: some epidemiological considerations. Psychiatria Neurologia, Neurochirurgia 1969;72: 503-6.

13 House of Commons Social Services Committee. Community cure. London: HMSO, 1985. (Second report.)

14 Abrams P. Community care: some research problems and priorities. In: Barnes J, Connelly N, eds. Social care research. London: Policy Studies Institute and Bedford Square Press, 1978:78.

15 Bulmer M. Neighbours. Cambridge: Cambridge University Press, 1986:24.

16 World Health Organisation Working Group. Psychiatry and primary medical care. Copenhagen: WHO, 1973.

17 Bennett DH. Community mental health services in Britain. Am f Psychiatry 1978;130:165-70.

18 Goldberg DP, Huxley P. Mental illness in the community. London: Tavistock, 1980.

19 Shepherd M, Cooper B, Brown AC, Kalton GW. Psychiatric illness in general practice. London: Oxford University Press, 1966.

20 Clare AW. Psychiatry in dissent. London: Tavistock, 1980.

21 Strathdee G, Williams P. A survey of psychiatrists in primary care: the silent growth of a new service. $\mathcal{X} R$ Coll Gen Pract 1984;34:615-8.

growth of a new service. F R Coll Gen Pract $1984 ; 34: 615-8$.
Williams P. Clare AW. Changing patterns of psychiatric care. Br Med $\mathcal{J}$ 1981;282:375-7.

23 World Health Organisation. Mental health services in southern countries of the European region. Copenhagen: WHO, 1988. (Euro Reports and Studies, No 107.)

(Accepted 19 June 1989)
Pamela M Crawford, David I Shepherd

Bruising or abrasion of the forehead after a fall in elderly patients may point to an important hyperextension injury to the cervical spinal cord

North Manchester General Hospital, Manchester M8 6RB

Pamela M Crawford, MRCP, registrar

David I Shepherd, FRCP,

consultant neurologist

Correspondence to: $\mathrm{Dr}$ Shepherd.

BrMed f 1989;299:669-70
Severe hyperextension injuries to the cervical spine are a well recognised cause of tetraparesis in young adults. In the elderly, however, a fairly trivial injury to the neck can cause an unexpectedly severe neurological deficit. Doctors' lack of appreciation of an interaction between a minor hyperextension injury to the neck and pre-existing, often asymptomatic, cervical spondylosis can lead to delay in making a correct diagnosis. We describe one typical patient (case 1) in detail and report on six other patients who presented over six years to a neurological centre.

\section{Case reports}

CASE 1

An 81 year old woman with severe chest pain for which she took glyceryl trinitrate fell forward, striking her forehead, and was unable to move. She had no history of difficulty in walking or cervical root pain. Examination showed an abrasion on her forehead and periorbital bruising (figure) but no neurological deficit, despite her complaint of weak arms and legs. Twenty four hours later weakness of her arms and legs was noted and the Guillain-Barré syndrome diagnosed. On neurological referral 48 hours after admission she had evidence of a spastic paraparesis, brisk triceps jerks, inverted biceps and supinator jerks, and considerable weakness of all $\mathrm{C} 7, \mathrm{C} 8$, and $\mathrm{T} 1$ innervated muscles. Sense of vibration was absent at the ankles but retained at the knees, and spinothalamic sensation was lost up to C6. A catheter was inserted to drain her urine.

$x$ Ray films of the cervical spine showed severe spondylotic changes from $\mathrm{C} 3$ to $\mathrm{T} 1$, with considerable narrowing of the joint spaces and posterior osteophytes. Electrocardiograms and chest $x$ ray films were normal. She was fitted with a firm cervical collar. Her bladder function soon reverted to normal, and her leg function

\section{Lesson of the Week}

\section{Hyperextension injuries to the cervical cord in the elderly}

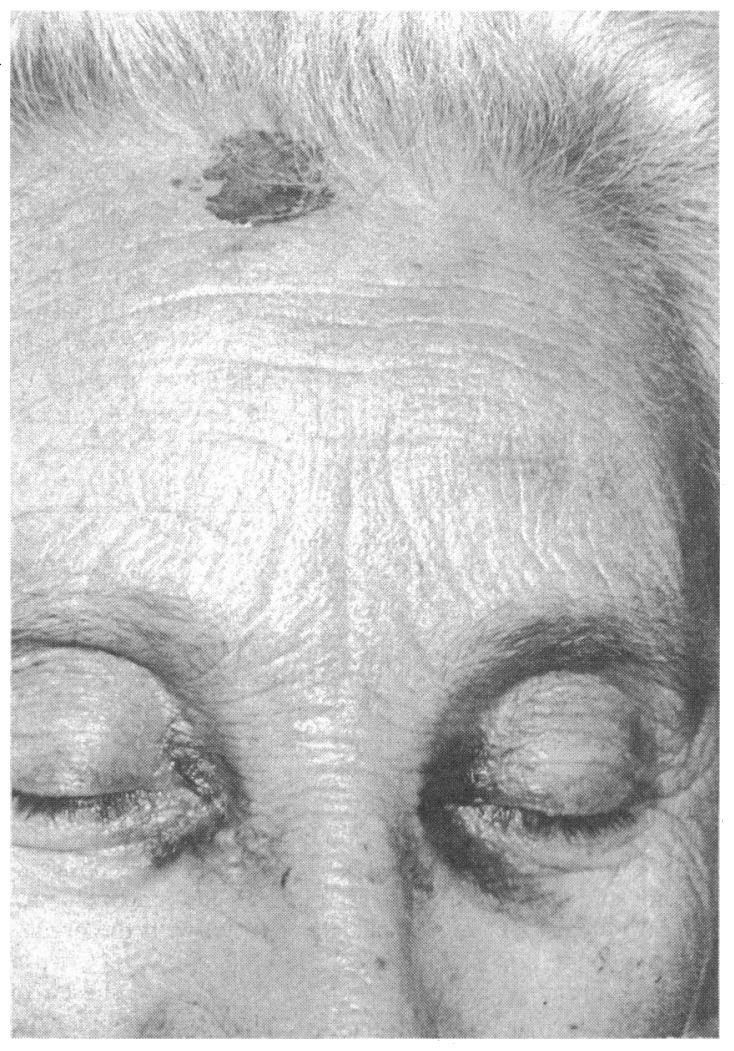

Abrasion on forehead and periorbital bruising after a fall in woman with previously undetected cervical spondylosis

improved substantially, but the function of her hands and arms improved only modestly. She was discharged 14 weeks after admission, ambulant with a walking frame but with her hands still weak and clumsy. 